\title{
Honesty Only Gets You So Far! The Effect of Two-sided Content on Re-purchase Intentions
}

\author{
Kıvılcım Döğerlioğlu Demir* \\ Sabancı Üniversity
}

\author{
Özge Turut** \\ Sabancl Üniversity
}

\author{
Ezgi Akpınar Uysal*** \\ Koç Üniversity
}

\begin{abstract}
A classical premise in the study of advertising is that two-sided ads that provide both positive and negative information about the products enhance purchase likelihood of the sponsored brands. Through a mix of analytical models and behavioral experiments, we show that two-sided content may in fact decrease the likelihood of re-purchase. This work sheds light on using two-sided content more effectively in the long-run by taking into account both consumers' own experiences and the effect of either ads or reviews.

Keywords: two-sided advertising, word of mouth, re-purchase, multi-method.
\end{abstract}

\section{Dürüstlük Bir Yere Kadar! İki Taraflı İçeriğin Tekrar Alım Niyeti Üzerindeki Etkisi}

\section{Özet}

Reklam araştırmalarındaki klasik öncüllerden biri, ürünlerin hem olumlu hem de olumsuz bilgi veren iki taraflı reklamların, sponsor markaların satın alma ihtimalini arttırmasıdır. Analitik modellerin ve davranışsal deneylerin bir karışımı ile, iki taraflı içeriğin aslında yeniden satın alma olasılığını azaltabileceğini gösteriyoruz. Bu çalışma, hem tüketicilerin kendi deneyimlerini hem de reklamların veya incelemelerin etkisini göz önüne alarak, iki taraflı içeriği uzun vadede nasıl daha etkili bir şekilde kullanılacağına 1şı1k tutmaktadır.

Anahtar Kelimeler: iki taraflı reklam, ă̆ıdan ă̆ıza reklam, tekrar satın alma, multi-disipliner.

I magine you come across the following ad for a mouth wash. "Introducing the RM mouthwash. RM kills all the germs in your mouth. We must admit it has a bitter taste, though". This ad has a two-sided message, disclaiming both a negative (bitter taste) and a positive aspect (effective in killing germs) of the product. You decide to

\footnotetext{
* Kıvılcım Döğerlioğlu Demir is an Assistant Professor in the School of Management at Sabancı Universty, Orhanlı, Tuzla, 34956, Istanbul, Turkey. E-mail: kivilcimdd@sabanciuniv.edu

** Özge Turut is an Assistant Professor in the School of Management at Sabancı University, Orhanlı, Tuzla, 34956 Istanbul, Turkey. E-mail: ozget@sabanciuniv.edu

*** Ezgi Akpınar Uysal is an Assistant Professor in the Graduate School of Business at Koç University, Rumelifeneri Mahallesi, Rumelifeneri Yolu, 34450, Sarıyer, Istanbul, Turkey. E-mail: eakpinaruysal@ku.edu.tr
} 
purchase the RM mouthwash. You thought that it has a bitter taste, however, based on your experience you later felt that it is indeed quite effective in killing germs. Would you consider buying an RM mouthwash again in the future?

Consumers are informed about products from ads such as the one described above, but ads are not the only source. Consider that you look for a hotel to stay in during your next vacation and read consumer reviews. You might read a consumer review that talks positively about the hotel (i.e., The hotel is neat and very close to all important attraction points) or read a two-sided review that claims both negative and positive aspects (i.e., The rooms are very small and the breakfast is quite limited but the hotel is neat and very close to all the important attraction points.) Imagine you decide to go to the hotel with the two-sided review. You indeed agree with the positive aspects but thought the room was small and the breakfast was quite limited. Based on your own experience, would you consider going to this hotel again in the future?

Research has shown that compared to ads that only present positive information, two-sided ads (providing negative information along with positive information), enhance disposition toward products (Pechmann, 1992; see Eisend, 2006, for a review). For example, when Listerine (the mouthwash brand) claims that the product is very effective in killing bacteria (a positive aspect) but also acknowledges that it has a bitter taste (a negative aspect), the brand evaluations should be more favorable, compared to when Listerine claims only the positive aspect (Pechmann, 1992). Although consumers use ads and consumer reviews as important sources of information, there is emerging evidence about distrust towards them.

Consumers become more suspicious towards ads and often show reactance towards advertising (Darke and Ritchie 2007; Rumbo 2002). Similar to advertising, trust towards consumer reviews has become an important issue. Although consumers trust consumer reviews more than advertising when making decisions (Nielsen, 2015), there is emerging concern about consumer reviews (Anderson and Simester 2014). Consumers become more aware of fake reviews in which a business might create positive fake reviews for themselves or negative fake reviews for their competitors (Luca and Zervas, 2016). Given the increasing trust issues concerning ads and reviews, companies are paying more attention on the content provided about their products or services.

One way to build trust towards ads and consumer reviews might be using two-sided content. It has been shown that consumers are likely to purchase products after being exposed to two-sided messages. When a negativity associated with the product is disclosed along with positive content, consumers not only conclude that the advertiser is telling the truth but also tend to focus more on the positive aspect. When the ad admits a rather negative aspect along with a positive attribute, the positive gains more prominence. Using two-sided ads makes products appear more trustworthy and builds trust towards advertising (Etgar and Goodwin, 1982).

Although there is vast information about the effects of two-sided content (see Eisend 2006 for a review), less is known about the impact in the later stages of the consumer 
buying decision process. ${ }^{[1]}$ It is clear that customers that repurchase and recommend products are the most profitable customers (Reichheld, 2003; Kumar, Petersen and Leone 2007). There is heartening work that shows the consequences of repeat purchase behavior (Dawes, Meyer-Waarden and Driesener 2015), yet there is scarce work understanding the effect of content such as advertising and consumer reviews on repeat purchase behavior. This work also addresses companies' goals to achieve repeat purchase behavior. After all, companies do not know in advance whether the consumers will in fact realize or experience the negative features they claim. Therefore, it would help companies to learn whether using two-sided ad claims may inadvertently hold back consumers from re-purchasing the product or not. Given the rising interest in achieving trust in ads and consumer reviews, understanding the impact of two-sided content would help both companies and consumers' welfare.

When consumers make (re)-purchase decisions, they count on three influential factors: marketers (i.e., ads), consumer reviews (Zhang, Ma and Cartwright, 2013) and their prior information (i.e., experiences and beliefs) together (Simonson and Rosen, 2014). This paper examines the effect of two-sided content on product re-purchase taking into account the three influential factors (ads, consumer reviews and their experiences) together. To do so, we explore the effect of two sided ads and two-sided consumer reviews and combine them with consumers' own experiences.

We make three main theoretical contributions. First, prior research has investigated the effect of two-sided ads on initial purchase, yet there is no research so far that has combined the effect of personal experience and content ads (both ads and consumer reviews) on downstream product related outcomes (i.e., re-purchase).

Second, we deepen understanding on using two-sided content in consumer reviews. Reviews are important sources of information for consumer purchase decisions (Godes and Mayzlin 2009; Goldenberg et al. 2009). Although word of mouth research has investigated the effect of positive and negative reviews extensively (see, Babic et al. 2015; East, Hammond and Lomax 2008), there is no research to date that has investigated the effect of two-sided reviews (positive and negative reviews at the same time). It has been shown that negative reviews are valued more than positive reviews (i.e., negativity bias) and have a more positive impact on product sales (Chen and Lurie 2013, Basuroy, Chatterjee and Ravid 2003, and Chevalier and Mayzlin 2006), yet no work has combined positive and negative reviews to test their effects on product related outcomes (re-purchase and recommendation).

Third, we use multi-methods to explore our research question. First, in order to develop our hypotheses regarding the influence of two-sided content on re-purchase, we develop an analytical model based on a behavioral economic paradigm (i.e., Liu 2013; Trautmann and Van De Kuilen 2015). Second, in order to test our predictions laid

[1] The consumer buying decision process consists of four main stages: 1. Need recognition, 2. Information search, 3. Alternative evaluation, Purchase decision, 4. Post-purchase behavior. In the information search stage, consumers acquire information through ads, consumer reviews and other sources. In the post-purchase behavior stage, consumers show re-purchase and recommendation behaviors. 
out in an analytical model, we use experimental behavioral studies. This work creates a bridge between analytical modeling and experimental evidence in order to solve an under-researched marketing phenomenon.

Overall, this work has important implications for both advertisers and social media experts for using two-sided content that will boost consumer re-purchase intentions.

\section{The Effect of Two-Sided Content on Purchase Likelihood}

Extant research on two-sided advertising shows that two-sided messages work better than one-sided ads when it comes to initial purchase intentions (Eisend 2006), particularly when the ad message contains related attributes (Bohner et al. 2003). Two-sided ads emphasize positive attributes of the product while disclosing unfavorable aspects (Pechmann, 1992). Disclosing negative information makes the positive aspects more pronounced and helps consumers perceive the positive attribute as more favorable, enhancing overall brand evaluations. Recent research on the blemishing effect echoes Pechmann (1992), suggesting that negative information that follows positive information increases the salience of the initial positive information, especially under low effort processing conditions (Ein-Gar et al., 2012). When consumers are exposed to two-sided content, they tend to make a trade-off and let go some negative traits to get more of the positive traits. Because consumers rely on correlational inferences (Pechmann, 1992), the presence of a negative claim leads to inferences that the positive characteristic is -in effect- at a more desirable level. This is especially applicable to ads that disclose traits that can be evaluated only after purchase (Eisend 2006; Pechmann 1992). In other words, some information on negative experience attribute (i.e., bitter taste) would strengthen the argument and beliefs about experience traits (i.e., effective in killing germs).

We argue that though two-sided content may be effective for initial purchase decisions, it may backfire on the second purchase occasion. Two-sided content makes the correlational link between positive and negative aspects more pronounced (compared to one-sided content). We argue that though disclaiming a negative attribute may be effective for initial purchase decisions, this very strategy may not hold on the second purchase occasion. Since the two-sided ad makes the negative correlational link between the positive attribute and the negative attribute more pronounced (compared to a onesided claim), consumer expectations from the rival product increases if they suspect that the rival product may have the same negative feature. This effect of two-sided advertising on the consumer's belief regarding the rival brand may reduce the repeat purchase likelihood of the sponsored brand, especially when the consumer does not have the best experience with the sponsored brand after using it.

To examine the impact of two-sided content on re-purchase intentions, we first develop an analytical framework and then test our predictions using behavioral laboratory experiments. 


\section{Analytical Model Setup}

Consider two-competing firms $\left(\mathrm{F}_{1}\right.$ and $\left.\mathrm{F}_{2}\right)$ each selling one new product priced as $p$. These products have one positive experiential attribute (i.e., effective in killing germs) and possibly one negative experiential attribute (i.e., tastes bitter). Consumers do not know whether a new product has the negative attribute before being exposed to an ad or a review. They think that with probability $\frac{1}{2}$ a new product has the negative attribute and with probability $\frac{1}{2}$ it does not have the negative attribute. If a product has the negative attribute consumers receive a disutility of $-b$. A new product's positive attribute may give consumers a high utility, medium utility, or a low utility. Neither consumers nor the firms know how much consumers will enjoy the positive attribute. We normalize the medium level of utility to 1 . Then, the low level utility is equal to $(1-\Delta)$, where $1>\Delta>b$, and the high level utility is equal to $(1+\Delta)$. Consumers do not realize the level of utility they will receive from the positive attribute till they use the product. However, they think that there is a negative correlation between the positive attribute and the negative attribute. Specifically, if a product has the negative attribute then with probability $1-\varepsilon$ consumers receive utility of 1 and with probability $\varepsilon$ consumers receive utility of $1+\Delta$ from the positive attribute. However, if the new product does not have the negative attribute then with probability $x$ consumers receive utility of $1-\Delta$ and with probability $(1-x)$ consumers receive utility of 1 from the positive attribute, where $x>\varepsilon$.

Consider $F_{1}$ has the negative attribute and wants to decide whether to promote two-sided content (ad or reviews) or one-sided one. The following scenarios should be considered before making a decision:

\section{When $F_{1}$ Promotes One-sided Content:}

If the firm engages in one-sided advertising (or reviews) then it only mentions that the consumers will receive high utility from its positive attribute (i.e., our food tastes great). Since the positive attribute is experiential and there is no way to verify for a consumer the amount of utility he will receive before usage, a firm cannot credibly communicate the level of utility consumers will receive from its positive attribute in its message. Thus, we assume that consumers do not believe any comment made about the positive attribute and make their purchase decisions based on their prior beliefs. Therefore, after being exposed to one-sided content, consumers' utility from $\mathrm{F}_{1}$ 's new product and $\mathrm{F}_{2}$ 's new product are equal to $\frac{1}{2}(1+\varepsilon \Delta-b)+\frac{1}{2}(1-x \Delta)-p$ and to $\frac{1}{2}(1+\varepsilon \Delta-b)+\frac{1}{2}(1-x \Delta)-$ prespectively. Thus, consumers are indifferent between the new products.

\section{When $F_{1}$ promotes two-sided content:}

If $\mathrm{F}_{1}$ engages in two-sided advertising (or reviews) it reveals that it has the negative attribute. The extant literature shows that when a consumer is exposed to a two-sided message, which mentions negatively correlated positive and negative attributes, consumers engage in correlational inference and their expectation from the positive expe- 
riential attribute increases (Pechmann, 1992). In the light of this consumer behavior, in our model we assume that after being exposed to $\mathrm{F}_{1}$ 's two-sided content, consumers update their prior belief and think that if a new product has the negative attribute with probability $y$ they will receive utility of $(1+\Delta)$ and with probability $(1-y)$ they will receive utility of 1 from the positive attribute, where $y>\varepsilon$. As a result, when $\mathrm{F}_{1}$ engages in two-sided advertising or reviews, consumers' utility from $\mathrm{F}_{1}$ 's new product and $\mathrm{F}_{2}$ ' $\mathrm{s}$ new product are equal to $1+y \Delta-b-p$ and to $\frac{1}{2}(1+y \Delta-b)+\frac{1}{2}(1-x \Delta)-p$ respectively. Therefore, $\mathrm{F}_{1}$ will find it profitable to engage in two-sided content only if $(y+x) \Delta>b$ because then consumers will prefer to buy $\mathrm{F}_{1}$ 's new product.

However, we know that in many product categories consumers need to repeat-purchase. Thus, in our model we assume that after buying and experiencing a new product in the first period consumers are again in the market to buy another unit in the same product category in the second period. Figure 1 illustrates the timeline of the game.

Figure 1

Time-line for Re-purchase after Two-sided or One-sided Content

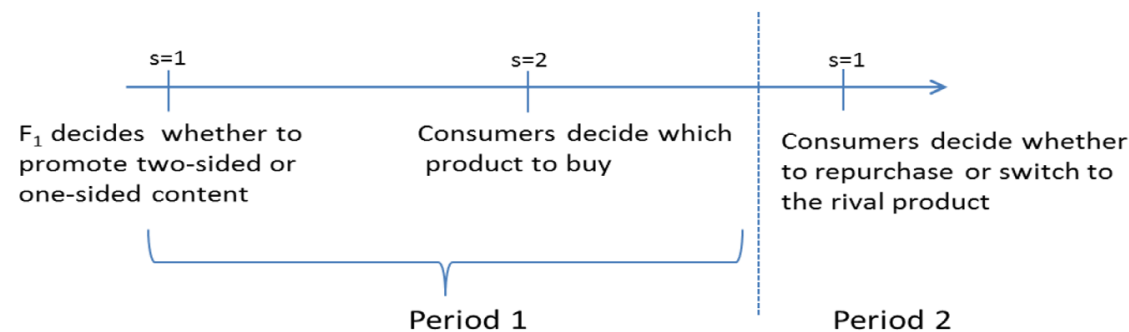

\section{When $F_{1}$ is purchased and negative attributes are experienced:}

Consider the case in which consumers who purchased $F_{1}$ 's new product in the first period received utility of $1-b-p$ after using it. This implies that $\mathrm{F}_{1}$ 's new product was good, but not great.

One-sided content: If $\mathrm{F}_{1}$ engaged in one-sided content in the first period then the consumers who purchased its new product in the first period will think that if they switch to $F_{2}$ 's new product in the second period they will receive utility of $\frac{1}{2}(1+\varepsilon \Delta-b)+\frac{1}{2}(1-x \Delta)-p$. Thus, $\mathrm{F}_{1}$ 's consumers will prefer to repeat purchase from $\mathrm{F}_{1}$ if $(x-\varepsilon) \Delta>b$.

Two-sided content: If $\mathrm{F}_{1}$ engaged in two-sided content in the first period then the consumers who purchased its new product in the first period will think that if they switch to $\mathrm{F}_{2}$ 's new product in the second period they will receive utility of $\frac{1}{2}(1+y \Delta-b)+\frac{1}{2}(1-x \Delta)-p$. Therefore, $\mathrm{F}_{1}$ 's consumers will prefer to repeat purchase from $\mathrm{F}_{1}$ if $(x-y) \Delta>b$. Note that $(x-\varepsilon) \Delta>(x-y) \Delta$. 
Finally, note that if consumers who purchased $F_{1}$ 's new product in the first period received utility of $1+\Delta-b-p$ after using it then they would prefer to repeat purchase it regardless if $F_{1}$ engaged in two-sided content or one-sided content. Therefore, by comparing the cases of one-sided content and two-sided content we conclude that if consumers do not have the best experience with the new product after using it, two-sided messages decrease their intentions to re-buy it. Therefore, we hypothesize the following:

$\mathbf{H}_{1}$ : Consumers will be less likely to re-purchase a product when exposed to two sided content (ads or consumer reviews) compared to when exposed to one-sided content.

While our analytical framework is supportive, it has certain limitations. First, it carries certain assumptions as in many models. Second, we cannot infer causality. To overcome these potential limitations, next we conduct behavioral experiments to test our predictions.

\section{Study 1}

In Study 1, we manipulate ad types (one sided ad versus two sided ads) and examine re-purchase intentions. We test whether compared to one sided ads, two sided ads lead to lower willingness to re-purchase products.

\section{Method}

We manipulated ad type through ad content (one-sided vs. two-sided) promoting a fictitious ice-cream brand. The one-sided ad reads as follows: "Introducing JP Barnaby's ice cream. Our ice cream is so delicious". The two-sided ad reads as follows: "Introducing JP Barnaby's ice cream. Our ice cream is so delicious but a bit heavy."

Participants $(\mathrm{N}=83)$ recruited from Mechanical Turk completed the study in exchange for monetary payment. First, participants were randomly assigned to one of the two ad types (one-sided or two-sided). Next, all participants were asked to imagine that "You've purchased and tried the ice cream and thought that it was delicious ${ }^{[2]}$ but a bit heavy." Finally, participants indicated their likelihood of repurchasing JP Barnaby's ice cream using a 7 point scale $(1=$ not likely; $7=$ very much likely $)$.

\section{Results}

We examined how ad type (one sided versus two-sided) influenced re-purchase likelihood. Consistent with our theorizing, compared to the one-sided ad $\left(M_{\text {one--sided ad }}=\right.$ 6.17; $S D=.95)$, the two-sided ad $\left(M_{\text {two-sided } a d}=5.23 ; S D=1.39\right)$ decreased willingness to re-purchase the product, $\left(F(1,81)=14.17, p=.00, \eta^{2}=.15\right)$.

\section{Discussion}

Study 1 provides the first empirical evidence that supports our prediction. While research suggests that two-sided ads boost product purchases (compared to one sided

[2] In both Study 1 and Study 2, drawing from (Eisend, 2006) and (Pechmann, 1992), we employed a negative experience attribute to reinforce the argument presented in the ad. Furthermore, we utilized highly correlated attributes to ensure correlational inferences (Pechmann, 1992). 
ads), we show that this effect might reverse when consumers try the product and experience the negative aspects themselves.

One could imagine that it was the content of the ad rather than the manipulation that affected our results. First, many consumers have the perception that tasty food is unhealthy (Mai and Hoffman 2015) and that is why the tastiness and heaviness of the ice-cream could be positively correlated if heaviness is not perceived as a negative feature. Although stimuli about ice-cream has been used in two sided content literature (Pechmann, 1992), in the next series of studies we used other product categories (i.e., mouth wash and hotel) to assure that it was not the ad content but the manipulation itself that drives our effects.

Second, one could argue that ice-cream is a promotion-focused product (providing pleasurable experiences rather than avoiding negative outcomes), thus showing positive features in one-sided ads might have been more effective for the ice-cream category. Therefore, using other product categories including a prevention-focused product (i.e., mouthwash), we wanted to rule out that explanation. Moreover, two-sided ads have been shown to boost purchase under promotion focused contexts (Cornelis 2013; Cornelis, Cauberghe and De Pelesmacker, 2014; Florack et al. 2009), yet there has been no research done for re-purchase intentions that also takes into account consumer experiences. While it is not a theoretical test, we conducted an ancillary study and a mathematical model (please see Appendix) that validated the effect of promotion versus prevention focus on re-purchase intentions.

Ancillary analyses. Participants $(\mathrm{N}=95)$ recruited from Mechanical Turk completed the study in exchange for monetary payment. First, participants were randomly assigned to one of the two priming conditions (promotion or prevention focus). The promotion system was made temporarily more accessible by priming a person's ideals and the prevention system was made more salient by priming obligations and duties adapted from the procedure used in Higgins et al. (1994) and Pham and Avnet (2004). After the priming procedure, participants saw the following two- sided ad message "Introducing JP Barnaby's ice cream. Our ice cream is so delicious but a bit heavy." Participants then read the following description of the ice cream experience "You've purchased and tried the ice cream and thought that it was delicious but a bit heavy." Finally, all participants were asked to answer the following item 'Based on your initial purchase experience, what is your likelihood of purchasing JP Barnaby's ice cream again?' (1=not likely; $7=$ very much likely). We found a main effect of regulatory focus on repeat purchase likelihood $\left(F(1,93)=3.99, p=.04, \eta^{2}=.04 ; M_{\text {promotion focus }}=4.71, S D=1.50 ; M_{\text {prevention focus }}\right.$ $=4.07, S D=1.55$ ). Our findings are in line with Florack et al. (2009). Participants were more likely to re-purchase the ice cream under promotion focus compared to prevention focus. While ancillary results only hold as a replication of previous findings in the context of re-purchase, this study provides additional insight on how to boost re-purchase intentions through promotion focus that can be lowered due to two-sided content.

In the next study, we used a prevention focused product category (mouthwash). This helps us show that the effect of the two-sided ads lowering re-purchase intentions is not bound to promotion focused products, but also observed with other types of product categories. 


\section{Study 2}

Study 2 builds on Study 1 in two key ways. First, we used another product category (that is prevention focused). Second, we employed another sample of participants. Taken together, these provide further robustness and generalizability to our results. We test whether compared to one sided ads, two sided ads lead to lower willingness to re-purchase products.

\section{Method}

We manipulated ad type through ad content (one-sided vs. two-sided) promoting a fictitious mouthwash brand. The one-sided ad reads as follows: "Introducing RM mouthwash. RM kills all the germs in your mouth". The two-sided ad reads as follows: "Introducing RM mouthwash. RM kills all the germs in your mouth. We must admit it has a bitter taste, though."

Participants $(\mathrm{N}=68)$ were recruited from European university undergraduate students who completed the study in exchange for partial course credit. First, participants were randomly assigned to one of the two ad types (one-sided or two-sided). Next, all participants were asked to imagine the following scenario. "You've purchased and tried RM mouthwash and thought that it was effective killing the germs. You also thought it had a bitter taste." Finally, participants indicated their likelihood of repurchasing RM mouthwash using a 7-point scale $(1=$ not likely; $7=$ very much likely $)$.

\section{Results}

We examined how ad type (one sided versus two-sided) influenced re-purchase likelihood. Consistent with our theorizing, compared to the one-sided ad $\left(M_{\text {one-sided ad }}=\right.$ 4.42, $S D=1.8)$, the two-sided ad $\left(M_{\text {two-sided ad }}=3.03, S D=1.9\right)$ decreased willingness to re-purchase the product, $\left(F(1,66)=9.79, p=.00, \eta^{2}=.12\right)$.

\section{Discussion}

Confirming our theory and Study 1 results, this study further provides evidence that when consumers are exposed to two-sided ads and experience the negative features, they are less likely to re-purchase the product than when they are exposed to one-sided ads and experience the negative features. These findings suggest that once consumers experience the product, they no longer 'excuse the trade-off' between the positive and the negative products. This might in fact give advantage to comparable rivals (if there are any) in the given product category. In other words, two-sided ads may inadvertently benefit the rival once the consumer experiences the product.

\section{Study 3}

Study 3 tests the hypothesized effect of two-sided content in consumer reviews and their influence on re-purchase intentions. We test whether compared to one sided reviews, two sided reviews lead to lower willingness to re-purchase products.

We manipulated the consumer reviewer type through content (one-sided vs. twosided) promoting a fictitious hotel. The one-sided consumer review reads as follows: 
"The hotel is close to all the shops and restaurants. We had no difficulties communicating with the staff because they spoke several foreign languages. Our room was clean and spacious. We were also able to manually adjust the air-conditioning in our room. The food at the breakfast was very varied; there was a different buffet every day." The two-sided consumer review reads as follows: "The hotel is far away from all the shops and restaurants. We also had difficulties communicating with the staff because they spoke no foreign languages. Our room was clean and spacious. We were also able to manually adjust the air-conditioning in our room. The food at the breakfast was very varied; there was a different buffet every day."

Participants $(\mathrm{N}=89)$ recruited from Mechanical Turk completed the study in exchange for monetary payment. Participants were asked to imagine that they were going to book a hotel they have not visited before. Participants were randomly assigned to one of the two consumer reviews (one-sided or two-sided). Next, all participants were asked to imagine that they stayed in this hotel and their experience was similar to the review. Finally, participants indicated their likelihood of visiting this hotel again on a 7-point scale ( $1=$ not likely; $7=$ very much likely) and suggesting this hotel to someone else $(1=$ not likely; $7=$ very much likely $)$.

\section{Results}

We examined how review type (one sided versus two-sided) influenced re-visiting likelihood. Consistent with our theorizing, compared to participants that read one-sided reviews $\left(M_{\text {one-sided review }}=6.11, S D=.99\right)$, participants that read two-sided reviews $\left(M_{t w o-}\right.$ -sided review $=4.02, S D=1.70)$ were less likely to revisit the hotel, $(F(1,87)=48.48, p$ $\left.=.00, \eta^{2}=.59\right)$. Further, results for suggesting was similar to revisiting. Compared to participants that read one-sided reviews $\left(M_{\text {one-sided review }}=6.11, S D=.10\right)$, participants that read two-sided reviews $\left(M_{\text {one--sided review }}=3.84, S D=1.79\right)$ were less likely to suggest the hotel to others, $\left(F(1,87)=57.72, p=.00, \eta^{2}=.66\right)$.

\section{Discussion}

Confirming our theory and our earlier findings, this study provides additional evidence that when consumers are exposed to two-sided content (i.e., reviews) and experience the negative features, they are less likely to revisit the service (i.e., hotel), compared to when they are exposed to one-sided content and experience the negative features (see figure 2 for a summary of our results).

It is important to note that we have used two sided ads with declining format (positive followed by negative) in Study 1 and Study 2, whereas an improving format (negative followed by positive) in Study 3. Across the three studies, regardless of whether the content was declining versus improving, we found that two sided ads led to less favorable outcomes for the brands compared to one-sided ads. We have chosen to test the effect of negative first, then positive, given existing work (Shiv and Tormala, 2012) has shown that when negative information is added to a positive description in a review (the order of presentation first positive followed by negative), the negative content "blemishes" the product, and consumers are more likely to pick the products in which 
they receive content with positive content followed by negative information compared to when they receive positive content. In this research, we reverse the order (negative first and then positive), and show that the blemishing effect disappears for repurchase based on reviews and experiences.

Further, Labroo and Ramanathan (2007) demonstrate that when consumers experience the emotions in the campaigns, they have higher attitudes towards ads with declining emotions (positive followed by negative) compared to ads with improving emotions (negative followed by positive). Taking together the findings of Shiv and Tormala (2012) and Labroo and Ramanathan (2007), if the order in Study 3 was positive followed by negative, consumers might have higher attitudes towards the product and may be more likely to recommend it to others (compared to two sided ads negative followed by positive).

Figure 2

\section{How Two-sided versus One-sided Content Impacts Likelihood of Re-purchase}

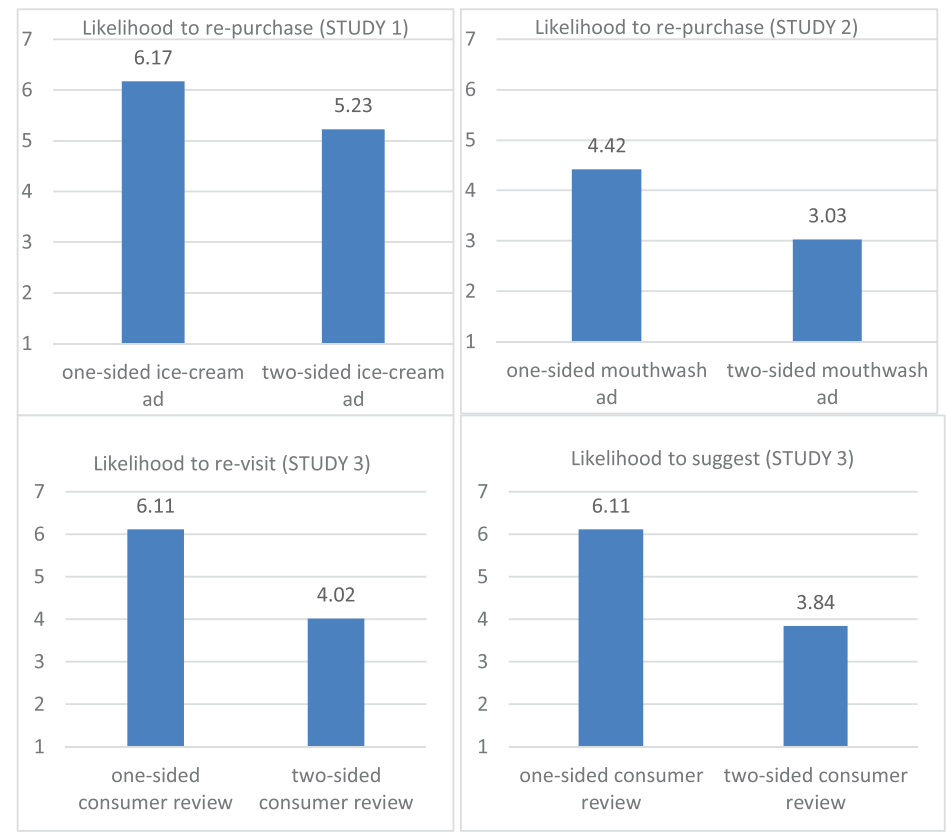

\section{General Discussion}

\section{Contributions}

This paper is the first to examine the impact of two-sided content (ads and reviews) on the repeat purchase decisions both theoretically and experimentally. The extant literature shows that two-sided ads increase the likelihood of initial purchase. However, we find that two-sided content decreases the likelihood of re-purchase. Specifically, being exposed to a two-sided ad or review, after the experience, the consumer might 
become less likely to re-purchase the product or use the service. One of the potential reasons for this reversal effect of two-sided content could be because unlike one-sided content, two-sided content increases consumer's expectation of the product category (and possibly the rival brand) by attenuating the negative correlation between the positive and negative attributes.

These findings make several theoretical contributions. First, we integrate work on advertising and word of mouth literature, shedding light on what makes content (ads and consumer reviews) lead to re-purchase behavior. Second, while work on two-sided advertising has focused on purchase behavior, to our knowledge this is the first paper that also incorporates the effect of consumers' experience on re-purchase behavior. Third, we laid out our predictions through an analytical model and validated them through experimental evidence. This work contributes to the need for multi-method work in the field of marketing by creating a link between analytical modeling and experimental evidence. Further, we also rule out several alternative explanations as well as provide ancillary tests. We demonstrate that our effects are not applicable to just a few products, but to several categories such as ice-cream, mouthwash and hotels. Moreover, our tests using different samples enhanced the robustness of our work.

The results have important managerial implications. Our findings suggest that twosided content leads to less re-purchase and recommendation. Especially, with products that cannot be tried before actual purchase (i.e., experience products, innovations or services such as hotels, health counseling), two sided content should be used with precaution. For such products, although not impossible, it is often hard to measure how much consumers might actually be satisfied. However, if the firm thinks that two-sided content is the best possible way to promote initial purchase, then priming consumers with a promotion focus might be useful, as suggested in the ancillary analyses.

Our findings have also important implications for consumer review platforms (i.e., Trip advisor) or for companies that provide consumers reviews (i.e. Amazon). While some review platforms receive consumer reviews in any format, others (i.e. Booking.com) require customers to indicate "positive" and "negative" comments in different spaces, which would result in two-sided reviews. Our results suggest that providing two-sided reviews might harm companies, considering the fact that their customers might not be satisfied with their experiences which may negatively impact re-purchase decisions.

\section{Further Research}

The results of our studies suggest several interesting research avenues for future research. First, while we show that two-sided content might decrease re-purchase and recommendation intentions, our results also show that a promotion focus may reduce the negative impact of two-sided content in the long-run. Future research should look into other situational and individual variables that may moderate this relationship.

Second, further research should explore ways to integrate the effect of two-sided reviews, two-sided ads and experiences. In our work, we have investigated the effect of ads and reviews separately on reviews. Emerging work in the word of mouth literature 
suggests that both ads and reviews impact each other, while having an effect on product related outcomes (Hewett et al. 2016). Further research should explore re-purchase and recommendation behavior when consumers are exposed to both two-sided ads and two-sided reviews. Could it be that receiving two-sided reviews from other consumers might provide expectations similar to one's own experiences, and therefore result in a negative effect on re-purchase that is attenuated (or reduced)? Further research should explore these three types of influences (ads, reviews and experiences) on product related outcomes simultaneously.

Finally, different ways of creating two-sided content should be explored to provide useful tools for marketers. Most advertising literature on two-sided content has focused on just valence (positive and negative). Yet, word of mouth literature suggests that it is not just valence, but also arousal (i.e. high arousal-angry and low arousal-sadness), that might shape why certain content gets shared more (Berger 2011). Further, research should explore different types of two-sided content (i.e., reviews with low arousal emotions and high arousal emotions).

\section{Conclusion}

In conclusion, this research illustrates how content (two-sided ads or two-sided consumer reviews) shapes consumers' willingness to re-purchase products. One reason marketers are excited about two-sided content is the possibility that consumers will be motivated to purchase products compared to when one-sided content is used. But, the current research demonstrates the importance of considering whether those purchases will convert to re-purchase after initial experiences. By showing the effect of two-sided content both in ads and consumer reviews, this paper demonstrates the aspects of content that might in fact harm the brand, rather than help it in the long run.

\section{References}

Anderson, E. and Simester, I.D. (2014). "Reviews without a Purchase: Low Ratings, Loyal Customers, and Deception," Journal of Marketing Research, 51(3): 249-269.

Berger, J. (2011). "Arousal Increases Social Transmission of Information," Psychological Science, 22(7): 891-893.

Bohner, G., Einwiller, S., Erb, H.P., and Siebler, F. (2003). "When Small Means Comfortable: Relations between Product Attributes in Two-sided Advertising," Journal of Consumer Psychology, 13(4): 45-463

Cornelis E. and Cauberghe, V. (2013). "Regulatory Congruence Effects in Two-sided Advertising," Advances in Consumer Research, 41: 28-292

Cornelis, E., Cauberghe, V., and De Pelesmacker, P. (2014) "Regulatory Congruence Effects in Twosided Advertising, ” European Journal of Marketing, 48(7-8): 1451-1465.

Dawes, J.G., Meyer-Waarden, L., and Driesener, C.B. (2015), "Has Brand Loyalty Declined? A Longitudinal Analysis of Repeat Purchase Behavior in the UK and USA," Journal of Business Research, 68: 425-432.

Derryberry, D. and Tucker, D.M. (1994). "Motivating the Focus of Attention. The Heart's Eye Emotional Influences in Perception and Attention," in M P. Niedenthal, S. Kitayama (eds), The Hearts Eye Emotional Influence in Perception and Attention: 167-196. Academic Press: San Diego, CA, 
Ehrenberg, A. S.C., Uncles, M.D., and Goodhardt, G.J. (2004). "Understanding Brand Performance Measures: Using Dirichlet Benchmarks," Journal of Business Research, 57(12): 1307-1325.

Ein-Gar, D., Shiv, B., and Tormala, Z.L. (2012). "When Blemishing Leads to Blossoming: The Positive Effect of Negative Information," Journal of Consumer Research, 38 (5): 846-859.

Eisend, M. (2006). “Two-sided Advertising: A Meta-analysis," International Journal of Research in Marketing, 23(2): 187-198.

Etgar, M. and Goodwin, S.A. (1982). "One-sided versus Two-sided Comparative Message Appeals for New Brand Introductions," Journal of Consumer Research, 8(4): 460-465.

Florack, A., Ineichen, S., and Bieri, R. (2009). "The Impact of Regulatory Focus on the Effects of Two-Sided Advertising," Social Cognition 27 (1): 37-56.

Florack, A. and Hartmann, J. (2007). "Regulatory Focus and Investment Decisions in Small Groups," Journal of Experimental Social Psychology, 43(4): 626-632.

Friedman, R.S. and Förster, J. (2001). "The Effects of Promotion and Prevention Cues on Creativity," Journal of Personality and Social Psychology, 81(6): 1001-13.

Hewett, K. William, R., Roland T. Rust,, and Harald, J.H. (2016). "Brand Buzz in the Echoverse," Journal of Marketing, 80(3): 1-24.

Higgins, E.T., Roney, C.J., Crowe, E., and Hymes, C. (1994). "Ideal versus Ought Predilections for Approach and Avoidance Distinct Self-regulatory Systems," Journal of Personality and Social Psychology, 66(2): 276-286.

Higgins, E.T. (1997). "Beyond Pleasure and Pain,” American Psychologist, 52(12): 1280-3000.

Kamins, M. A. and Marks, L.J. (1987). “Advertising Puffery: The Impact of Using Two-sided Claims on Product Attitude and Purchase Intention," Journal of Advertising, 16: 6-15

Labroo, A.A. and Suresh, R. (2007). "The Influence of Experience and Sequence of Conflicting Emotions on Ad Attitudes," Journal of Consumer Research, 33(4): 523-528

Lin, Y.C., Chang, C.A., and Lin, L.Y.F. (2012). "Self-construal and Regulatory Focus Influences on Persuasion: The Moderating Role of Perceived Risk," Journal of Business Research, 65(8): 1152-1159.

Luca, M. and Zervas, G. (2016). "Fake It Till You Make It: Reputation, Competition, and Yelp Review Fraud," Marketing Science, forthcoming.

Lui, M.W. (2013). “Utility Blindness: Why Do We Fall for Deals?,” Journal of Consumer Behaviour, 13(1): 42-49.

Nielsen. (2015). Global Trust in Advertising, last accesssed July 2016. https://www.nielsen.com/content/ dam/nielsenglobal/apac/docs/reports/2015/nielsen-global-trust-in-advertising-report-september-2015. pdf

Pechmann, C. (1992). "Predicting when Two-sided Ads will be More Effective than One-sided Ads: The Role of Correlational and Correspondent Inferences," Journal of Marketing Research, 29(4): 441-453.

Pervan, S.J. and Martin, B.A. (2012). "Development and Validation of the Consumer Disillusionment toward Marketing Activity Scale," Journal of Consumer Behavior, 11(5): 339-46.

Pham, M.T. and Avnet, T. (2004). "Ideals and Oughts and the Reliance on Affect versus Substance in persuasion," Journal of Consumer Research, 30(4): 503-518.

Poels, K. and Dewitte, S. (2008). "Hope and Self-regulatory Goals Applied to an Advertising Context," Journal of Business Research, 6 (10): 1030-1040. 
Roy, R. and Ng, S. (2012). "Regulatory focus and preference reversal between hedonic and utilitarian consumption," Journal of Consumer Behaviour, 11(1): 81-88.

Shiv, B. and Zakary T. (2012). "When Blemishing Leads to Blossoming: The Positive Effect of Negative Information," Journal of Consumer Research, 38(5): 846-859.

Smith, R.E. and Hunt, S.D. (1978). "Attributional Processes and Effects in Promotional Situations," Journal of Consumer Research, 5: 149-158.

Trautmann, S.T. and Van De Kuilen, G. (2015). "Reserve Price and Competing Bids: Reference Points for Product Evaluations in Online Auctions?," Journal of Consumer Behaviour, 14(4): 285-296.

Wang, J. and Lee A.Y. (2006). "The Role of Regulatory Focus in Preference Construction," Journal of Marketing Research, 43: 28-38.

Zhang, L. and Ma, B., and Cartwright, D.K. (2013). "The Impact of Online User Reviews on Cameras Sales," European Journal of Marketing, 47(7): 1115-1128. 


\section{APPENDIX}

\section{Ancillary Model Set-up}

Although it is a key theory test, we also developed a mathematical model that shows how consumers' regulatory focus moderates the effect of two-sided content on consumers' repeat purchase decisions.

When promotion focus is active, the presence and absence of positive outcomes become more important to the individual, and therefore, judgments and behaviors are regulated relative to these positive outcomes (Florack and Hartmann, 2007; Wang and Lee, 2006; Cornelis et al. 2014). As priming promotion focus highlights the desired features of a product and those that are related to approaching positive outcomes, we model consumer behavior with a promotion focus and a prevention focus as follows:

As suggested in our previous mathematical model, after being exposed to $F_{1}$ 's twosided advertisement, consumers with a prevention focus update their prior belief and think that if a new product has the negative attribute with probability $y$ they will receive utility of $(1+\Delta)$ and with probability $(1-y)$ they will receive utility of 1 from the positive attribute. However, consumers with a promotion focus update their prior belief and think that if the new product has the negative attribute with probability $y$ they will receive utility of $(1+\Delta)$ and with probability $(1-y)$ they will receive utility of 1 from the positive attribute and that if the new product does not have the negative attribute with probability $\bar{x}$ they will receive utility of $(1-\Delta)$ and with probability $(1-\bar{x})$ they will receive utility of 1 from the positive attribute, where $\bar{x}>x$. This implies that promotion focused consumers are more cautious about the absence of the negative attribute because it means not being able to receive a high level of utility from the positive attribute.

Thus, as in the main model set-up, after being exposed to two-sided content the prevention focus consumers will purchase $\mathrm{F}_{1}$ 's new product in the first period if $(x+y) \Delta>b$. Furthermore, the prevention focused consumers who purchased $F_{1}$ 's product in the first period and received utility of $1-b-p$ will repeat purchase $\mathrm{F}_{1}$ 's product in the second period if $(x-y) \Delta>b$.

However, after being exposed to two-sided content the promotion focused consumers will purchase $\mathrm{F}_{1}$ 's new product in the first period if $(\bar{x}+y) \Delta>b$. This happens because when $\mathrm{F}_{1}$ engages in two-sided content, promotion focused consumers' utility from $\mathrm{F}_{1}$ 's product and $\mathrm{F}_{2}$ 's product are equal to $1+y \Delta-b-p$ and to $\frac{1}{2}(1+y \Delta-b)+\frac{1}{2}(1-\bar{x} \Delta)-p$ respectively. Since $(\bar{x}+y) \Delta>(x+y) \Delta$ this result implies that two-sided ads are more effective for promotion focused consumers than for prevention focused consumers for the initial purchase. Given that the promotion focused consumers expect to receive utility of $\frac{1}{2}(1+y \Delta-b)+\frac{1}{2}(1-\bar{x} \Delta)-p$ from $\mathrm{F}_{2}$ 's new product, the promotion focused consumers who purchased $\mathrm{F}_{1}$ 's new product in the first period and received utility of $1-b-p$ will repeat purchase $\mathrm{F}_{1}$ 's product in the second period if $(\bar{x}-y) \Delta>b$, wher $(\bar{x}-y) \Delta>(x-y) \Delta$. Thus, two-sided ads are more effective for promotion focused consumers than for prevention focused individuals for the repeat purchase as well. 
Note that if consumers who purchased $\mathrm{F}_{1}$ 's new product in the first period received utility of $1+\Delta-b-p$ after using it, then they would prefer to repeat purchase regardless if they are promotion focused or prevention focused. 